\title{
Monte Carlo-based Stochastic Analysis Results for Coordination of Single-Phase Rooftop PVs in Low Voltage Residential Networks
}

\author{
Nelly Safitri ${ }^{1}$ - Farhad Shahnia ${ }^{2}$ - Mohammad A.S. Masoum ${ }^{1}$
}

Received: 9 September 2015 / Revised: 26 October 2015 / Accepted: 26 October 2015 / Published online: 20 November 2015

(C) Springer Science+Business Media Singapore 2015

\begin{abstract}
Installation of single-phase rooftop photovoltaic (PV) systems in low voltage (LV) residential feeders without controlling their ratings and locations may deteriorate the overall grid performance including reversed power flows, high losses and unacceptable voltage profiles. Therefore, in recent years the utilities have adopted limitations on the maximum allowable number of PVs in LV networks. To overcome these issues, this paper investigates the performance of a communication-based and intelligent voltage profile regulating technique under a Monte Carlo-based stochastic framework. This technique is applicable for LV residential feeders with single-phase rooftop PVs and relies on the availability of smart meters along the LV feeder to transmit phase voltage measurements to the controllers of the PV inverters. The objective of the voltage regulation technique is to minimize voltage unbalance along the feeder. The effectiveness of the voltage regulation technique are investigated in this paper by the help of MATLAB-based simulation studies.
\end{abstract}

Keywords Rooftop PV - Stochastic analysis - Monte Carlo $\cdot$ Residential feeder

\section{Introduction}

Most low voltage (LV) distribution networks were constructed a few decades ago and are reaching their capacity

Farhad Shahnia

farhad.shahnia@curtin.edu.au

1 Department of Electrical and Computer Engineering, Centre for Smart Grid and Sustainable Power Systems, Curtin University, Perth, Australia

2 School of Engineering, Murdoch University, Perth, Australia limits due to the natural load growth. Although voltages are usually well balanced at the supply side, they can become unbalanced at the customer level due to the unequal distribution of single-phase loads and PVs connected to the LV feeders [1]. Considering the fact that most of the residential rooftop PV systems are single-phase units, their integration into the three-phase networks might increase the unbalance issues due to their random locations and ratings [2]. Reference [3] indicates that rooftop PV installations will have minor effect on the voltage unbalance at the beginning of a LV feeder designed with engineering judgments; however, the voltage unbalance might increase at the end of the feeder to more than the standard limit. Moreover, the high number of rooftop PVs can change the direction of power flow and lead to voltage rise along the feeder. High penetration of rooftop PVs may also increase the harmonics in a LV feeder and lead to highly distorted voltage/current waveforms which need to be controlled or minimized by installation of an active or hybrid power filter [4]. These facts become the main issues and challenges that most electrical utilities are currently encountering.

To deal with the voltage rise and unbalance issues, many different techniques have been proposed in the literature. Reference [3] has concluded that a $16 \%$ increase in the capacity of the PV inverters is sufficient to accommodate the reactive power exchange that is required for voltage profile improvement in the LV feeders. Reference [5] has suggested a modified control scheme for the inverters of the rooftop PVs to represent a reactive power-voltage droop characteristic such that the PV inverters mimic the operation of a synchronous generator. References [6,7] have utilized droop-based and optimal control-based active power curtailment to prevent overvoltage conditions in LV feeders. Reference [8] has proposed to modify the control of the residential PV inverters to work at two different modes at 
daytime and evening periods. It is suggested that at daytime PVs generate active power and at evening/night periods, the $\mathrm{PV}$ inverters operate as a reactive power source to improve the voltage profile at network peak periods. Reference [9] has discussed the possibility of utilizing distribution transformers with on load tap changing (OLTC) mechanism to automatically step-up and step-down the transformer output voltage to prevent non-acceptable voltage drop and voltage rise while maximizing the penetration level of PVs in the $\mathrm{LV}$ feeder.

The authors have proposed an intelligent voltage regulation technique (VRT) in [10], which considers the availability of smart meters throughout the network. The proposed method is composed of three steps (sub-modules). First, the distribution transformer reduces the voltage at its secondary by the help of its OLTC capability such that the voltage along the feeder is within the allowable limits. This is verified by the voltage sensors installed at the beginning and end of the feeder to measure the voltage magnitude at these two ends. Following that, the inverters of the PVs are coordinated such that they exchange reactive power with the feeder to minimize the voltage unbalance at each bus. If reactive power exchange is not successful, the VRT applies active power curtailment as the last and final approach to minimize the voltage unbalance along the feeder. The VRT in [10] has only been investigated for a limited number of deterministic cases; however, due to the intermittency of the load demand and PV generation, a deterministic study is not sufficient to demonstrate the effectiveness of the VRT. Thereby, this paper focuses on the uncertainties and investigates the effectiveness of the VRT under a stochastic framework in which many different scenarios of load demand, PV penetration level and generation values are considered.

Monte Carlo is a technique that develops repeated random sampling to get statistical results and is commonly used to address uncertainties in power systems [11]. Monte Carlo as a statistical method has been used to validate the probabilities of overloads that may cause faults in [12]. It also has been used as the probabilistic analysis for capacity planning of smart grid at residential levels in [13] and is also used globally to study the LV feeders with high PV penetration [14-16]. Therefore, a Monte Carlo-based approach is selected to conduct the stochastic analysis in this research. The proposed approach in [10] is stochastically analysed for a typical LV feeder in MATLAB and its effectiveness are discussed. Thus, the main contribution of this paper is to validate the performance of the recently proposed VRT in [10] at difference penetration levels and ratings of PVs as well as their unequal distributions among the three phases of the LV feeder under a stochastic framework.

The rest of the paper is organized as follows: "Network Under Consideration" section introduces the network under consideration. The recently proposed VRT is briefly discussed in "Voltage Regulation Technique" section."Monte Carlo-based Stochastic Analysis" section presents the Monte Carlo-based stochastic analysis. Several MATLAB-based stochastic analysis cases are discussed in "Performance Evaluation" section to evaluate the performance of the VRT. "Conclusion" section discusses the limitation of the proposed method. The main conclusions of the paper are highlighted in the last section.

\section{Network Under Consideration}

The selected test network is a three-phase four-wire radial $\mathrm{LV}$ residential feeder, with $N$ buses, that is supplied from a three-phase three-wire medium voltage feeder through a three-phase Dyn distribution transformer, as shown in Fig. 1. The LV feeder is assumed to be a common multiple earth neutral (CMEN) system [17] in which the neutral wire is earthed at the distribution transformer as well as at the premises of each load. All residential loads are assumed as single-phase type, which are distributed equally among the three phases of the network. The LV feeder is assumed to be constructed from bare All Aluminium Conductor (AAC) overhead type that is distributed over cross-arms with vertical configurations over the poles. Assuming the after diversity maximum demand (ADMD) of $4.7 \mathrm{kVA}$ for each residential house and length of 400 meters for the lines, the transformer ratings and conductor cross sections are selected based on engineering judgments, using the Australian Standards [18]. It is to be noted that although this type of LV distribution networks is common in Australia and many parts of Asia, Europe and Africa, it is not the common practice in northern American countries.

All residential loads are assumed as constant power type for simplicity. It is to be noted that although the number of houses is same for all phases, their instantaneous power consumption is different which makes the system unbalanced. It is assumed that each house may have a rooftop PV system connection. However, the PVs may have different ratings, which will further make the system unbalanced.

The technical parameters for the network are provided in the Appendix. An unbalanced power flow technique, based on forward/backward sweep, is developed and used for power flow analysis, as discussed in [19].

\section{Voltage Regulation Technique}

An intelligent communication-based VRT is proposed by the authors in [10], as illustrated in Fig. 2, and is the combina- 


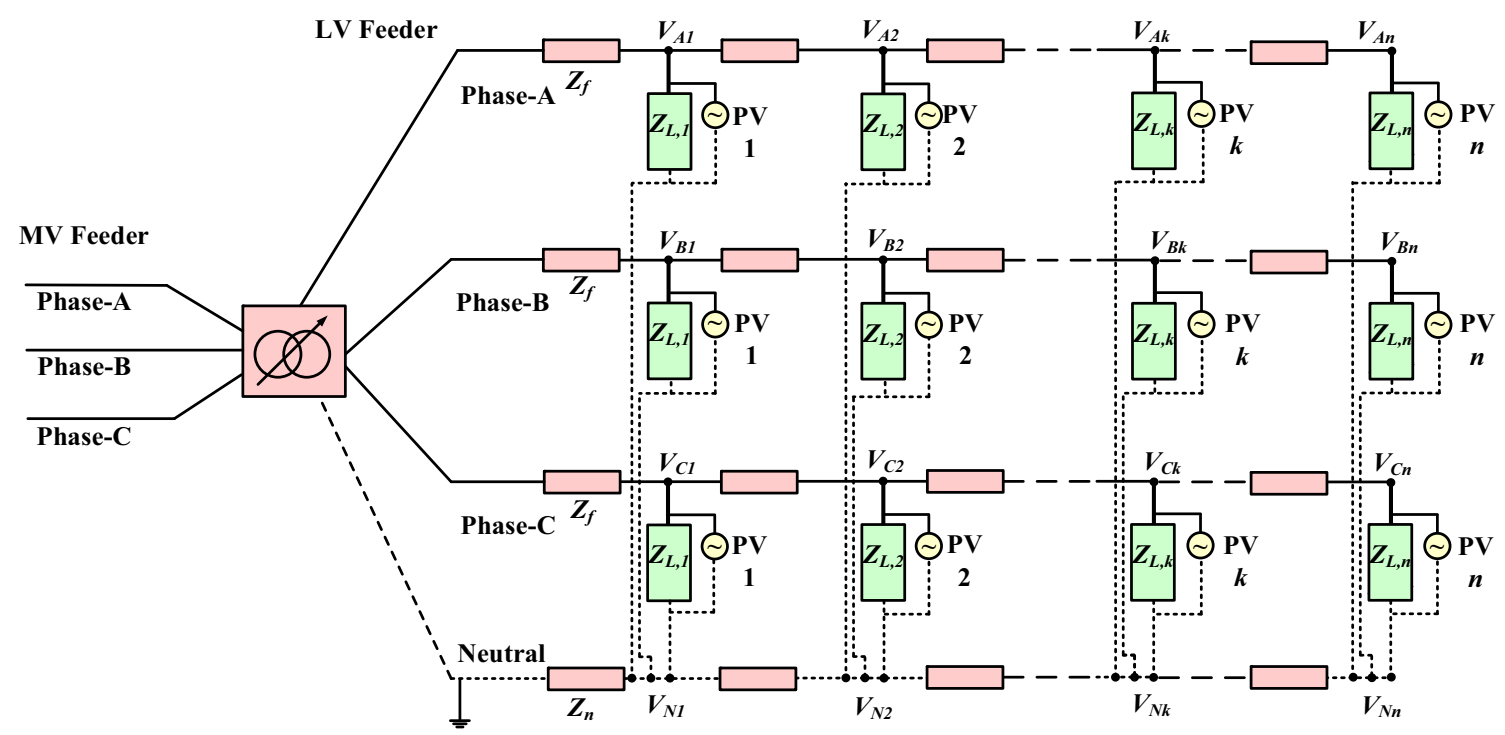

Fig. 1 The simulated three-phase unbalanced residential LV network with single-phase rooftop PVs

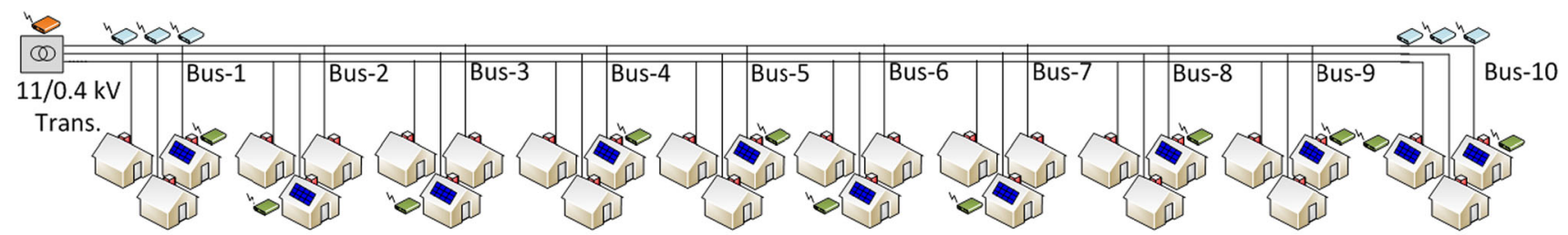

Master Controller $\diamond$ Voltage Measurement Sensors $\Leftrightarrow$ PV Inverter Controllers

Fig. 2 Schematic representation of the considered VRT

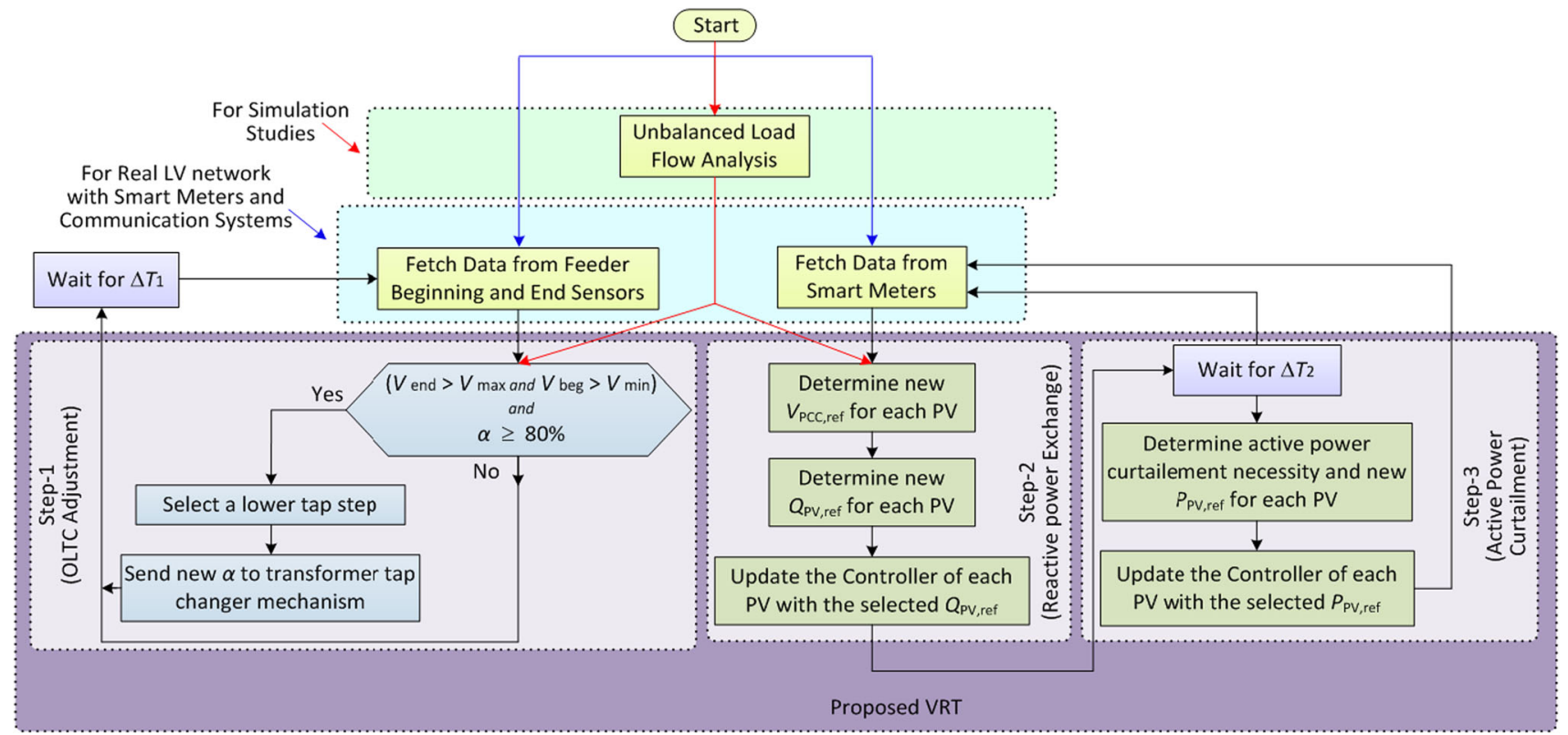

Fig. 3 Flow chart of the VRT composed of 3 steps of OLTC adjustment, distributed reactive power exchnage and active power curtailment

tion of distributed reactive power support and active power curtailment by the inverters of the rooftop PVs as well as the OLTC control of the LV transformer. The flowchart of the proposed intelligent method is shown in Fig. 3 and summarized below. The interested readers are encouraged to refer to [10] for more details. 


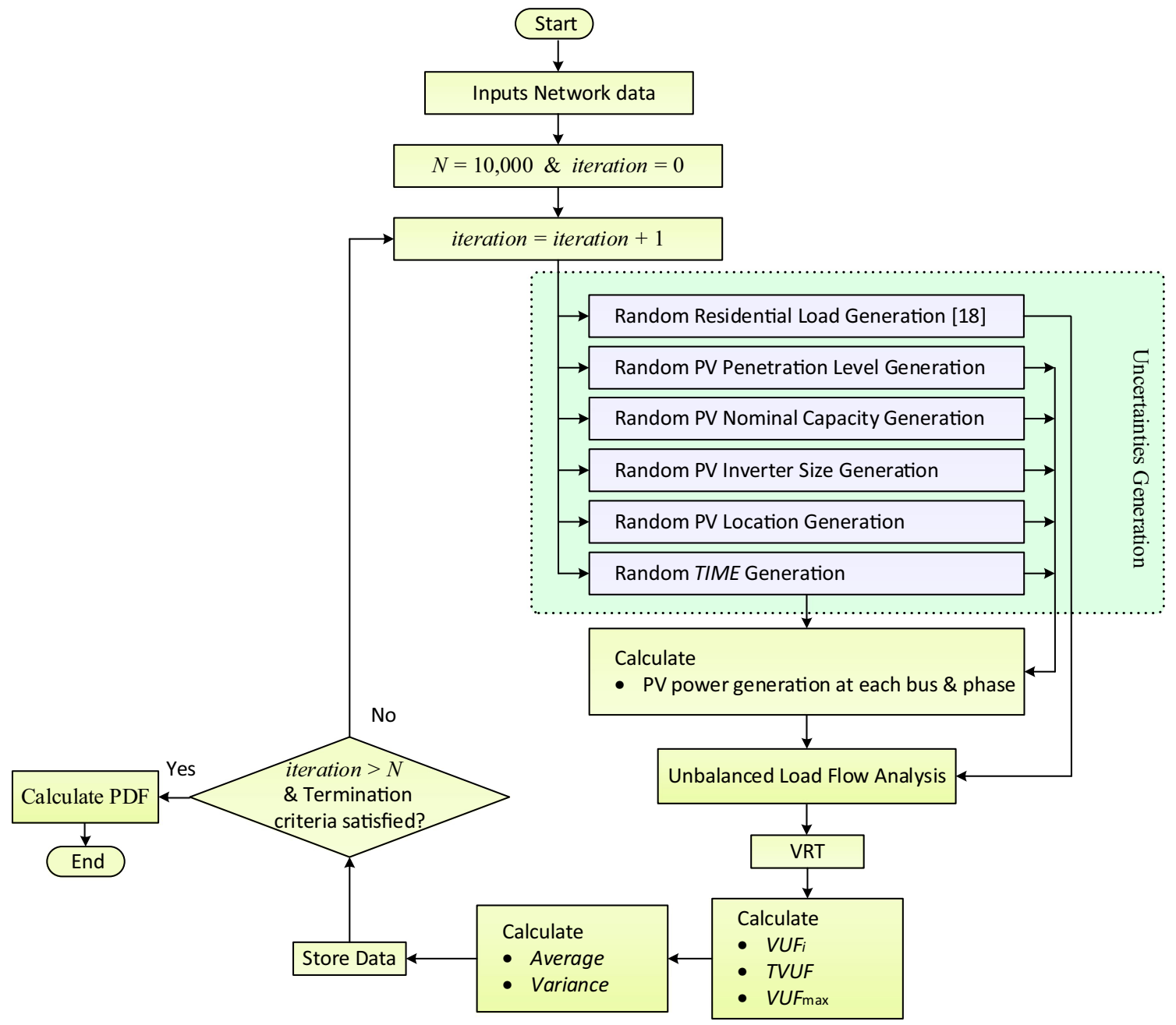

Fig. 4 Flow chart of the developed stochastic framework

\section{Step 1: Voltage Adjustment Using OLTC Transformer}

Voltage profile along the LV feeder should be kept within the recommended limits of 95 and $110 \%$ of the nominal voltage [17]. By utilizing a transformer with OLTC, the transformer secondary voltage can be increased or decreased such that the voltage all along the feeder is kept within the imits. This method is based on the assumption that two three-phase voltage sensors are installed in the network-one set at the beginning of the feeder and another set at the end of the feeder. Both of these voltage sensors are assumed to have data communication capability such as WiFi or ZigBee to transfer the measured phase voltages to the master controller, that is installed at the distribution transformer.

First, the feeder end voltage is monitored by the help of the installed voltage sensors and this data is transferred to the master controller. Once the voltage at feeder end reaches above the allowable limit, the master controller sends a proper command to the transformer tap changing system to select and activate a lower tap. Hence, the voltage all along the feeder reduces.

After this process, the feeder beginning voltage is monitored by the help of the installed voltage sensor and its data is transferred to the master controller. This voltage should be kept above the minimum allowable limit. Then, if the voltage at the end of the feeder is still above the maximum allowable limit, the process will be repeated to reasure the voltage all along the feeder is within the acceptable limit. Hence, by the help of a transformer with OLTC, the secondary voltage can be reduced down to a minimum of $80 \%$.

It is to be noted that the OLTC does not operate instantaneously. The system allows a time delay of $\Delta T_{1}$ (in few minutes range) between two consequent operations.

\section{Step 2: Voltage Regulation by Reactive Power Support}

Consider the LV feeder of Fig. 1 with 10 buses where each bus may have single-phase PVs. Currently, based on IEEE 
Fig. 5 Case of $100 \%$ PV penetration level, considered random residential demand for 30 houses over a $24 \mathrm{~h}$ period: (a) in time domain, (b) boxplot representation, (c) histogram representation (a) Random Active Power Demand of Each House in 24-hr
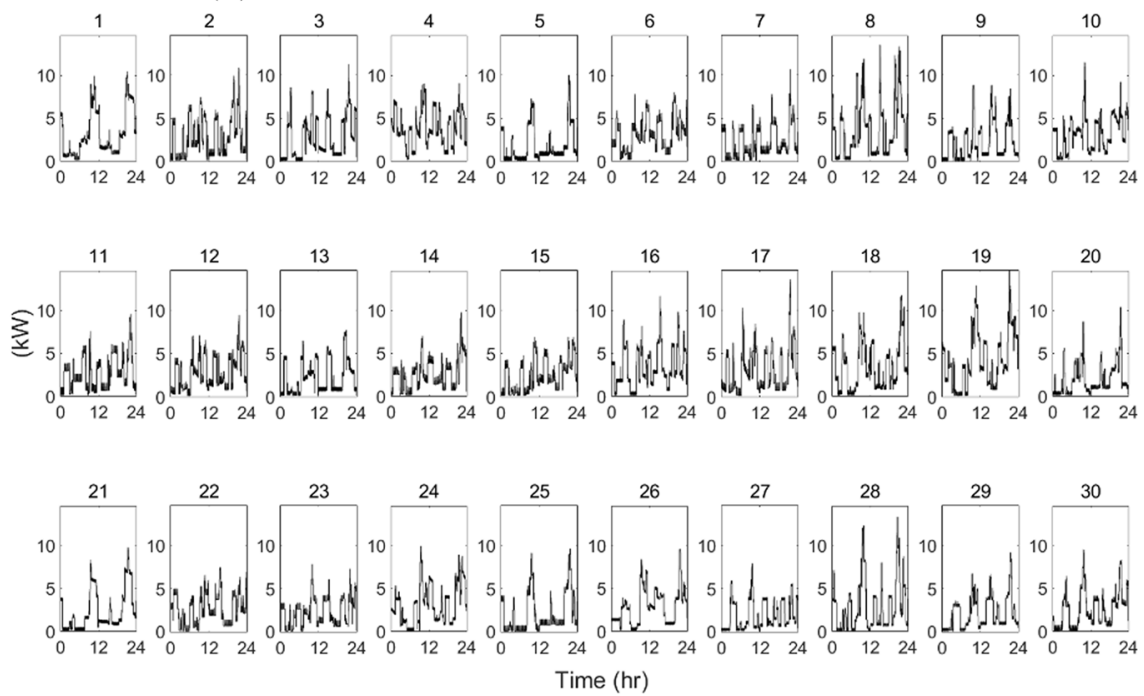

(b) Boxplot of Active Power Demand of Each House in 24-hr

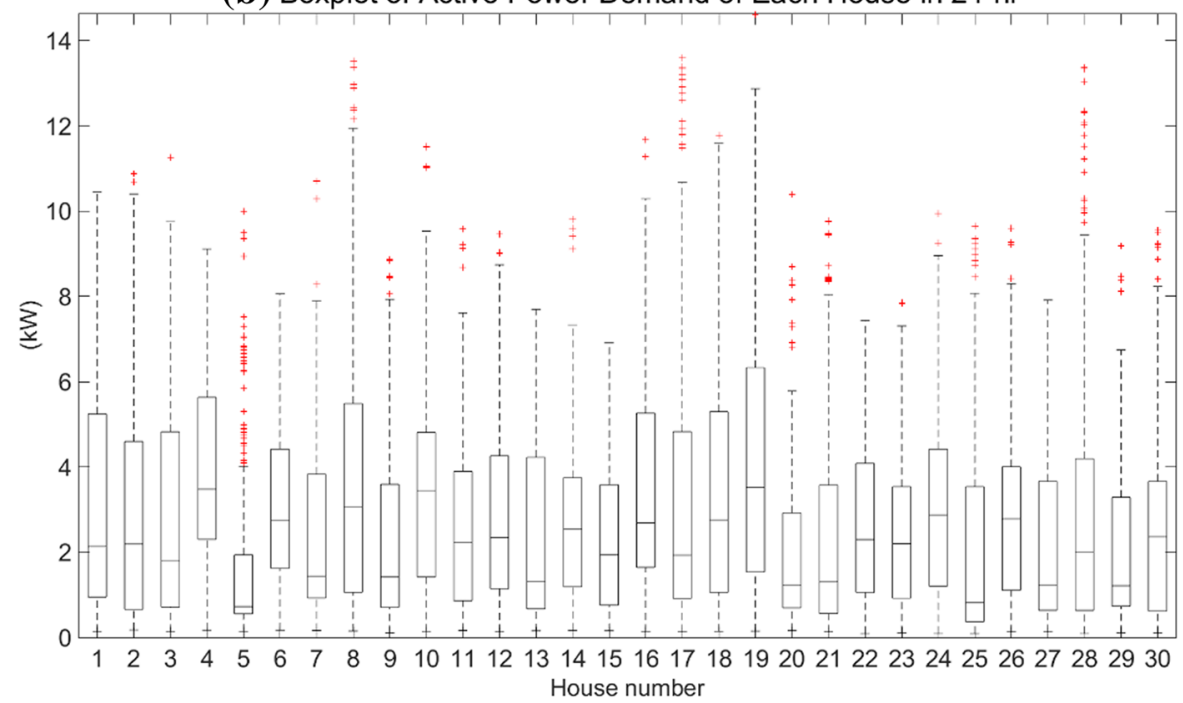

(c) Histogram of Active Power Demand of Each House in 24-hr

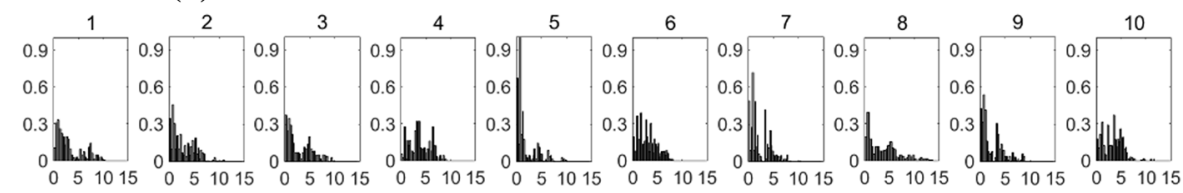

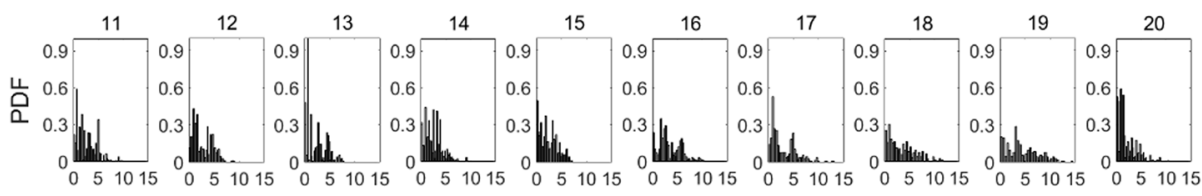

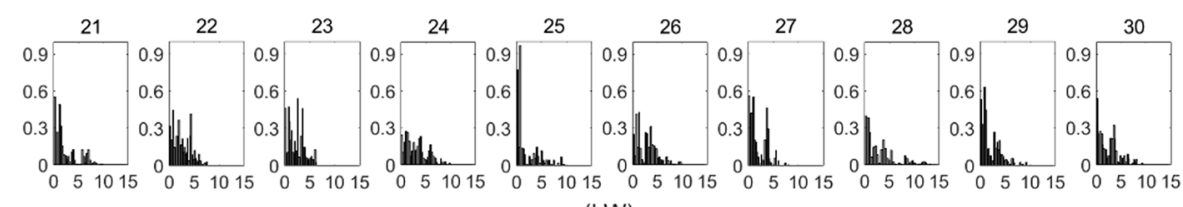

(kW) 
recommended practice for utility interface of PV systems [18], the PV inverters operate at constant output power mode. Under such conditions, they only inject current with unity power factor and do not affect the voltage at their PCCs. If the inverters are operated in voltage control mode, each PV inverter can correct its own PCC voltage to a desired value $\left(V_{\mathrm{PCC}, \text { ref }}\right)$ by injecting or absorbing the required amount of reactive power $\left(Q_{\mathrm{PV}, \text { ref }}\right)$. To minimize PCC voltage error from its reference, each PV inverter needs to exchange reactive power with the feeder to keep the voltage of its output equal to the desired value. This can be achieved in a decentralized method using the droop control strategy as [10]

$Q_{\mathrm{PV}, \text { ref }}=m\left(V_{\mathrm{PCC}, \text { ref }}-V_{\mathrm{PCC}}\right)$

where $m>0$ will be assigned by the reactive power-voltage $(Q-V)$ droop controller. The selected $Q_{\mathrm{PV} \text {,ref }}$ in (1) must be within the inverter capacity as

$-\sqrt{S_{\mathrm{PV}, \text { max }}^{2}-P_{\mathrm{PV}}^{2}} \leq Q_{\mathrm{PV}, \text { ref }} \leq \sqrt{S_{\mathrm{PV}, \text { max }}^{2}-P_{\mathrm{PV}}^{2}}$

where $S_{\mathrm{PV} \text {,max }}$ is the maximum apparent power of the PV inverter and $P_{\mathrm{PV}}$ is the active power supplied by the $\mathrm{PV}$ at that time. If the selected (required) $Q_{\mathrm{PV} \text {,ref }}$ is beyond the inveter maximum capability, it will be limitted to the maximum limits. $V_{\text {PCC,ref }}$ is dynamicllay calculated and updated to minimize the voltage unbalance among the three phases at every bus along the LV feeder as below [10]:

(1) If a PV is available on all three phases of bus $i, V_{\mathrm{PCC} \text {,ref }}$ at this bus is chosen equal to the average of the voltage magnitudes of the three phases, as

$$
V_{\mathrm{PCC}, \mathrm{ref}, i}=\left(V_{\mathrm{A}, \mathrm{i}}+V_{\mathrm{B}, \mathrm{i}}+V_{\mathrm{C}, \mathrm{i}}\right) / 3
$$

(2) If PVs are available only on two phases of bus $i$ (e.g. on phases "B" and "C"), $V_{\mathrm{PCC}, \text { ref }}$ at this bus is chosen equal to the voltage magnitude of the third phase (i.e. phase "A").

(3) If a PV is available only on one phase of bus $i$ (e.g. on phase " $\mathrm{A}$ "), $V_{\mathrm{PCC} \text {,ref }}$ at bus $i$ is chosen equal to the average of the voltage magnitudes of the other two phases, i.e.

$$
V_{\mathrm{PCC}, \mathrm{ref}, i}=\left(V_{\mathrm{B}, \mathrm{i}}+V_{\mathrm{C}, \mathrm{i}}\right) / 2
$$

(4) If no PV is available on any of the phases of bus $i$, then $V_{\mathrm{PCC}, \text { ref }}$ will not be defined for this bus since no PV is available.

Note that for each bus with rooftop PV, $V_{\mathrm{PCC}, \text { ref }}$ will be determined based on the data transmitted from the installed voltmeters at each phase to the rooftop PV controller throught the smart meters.

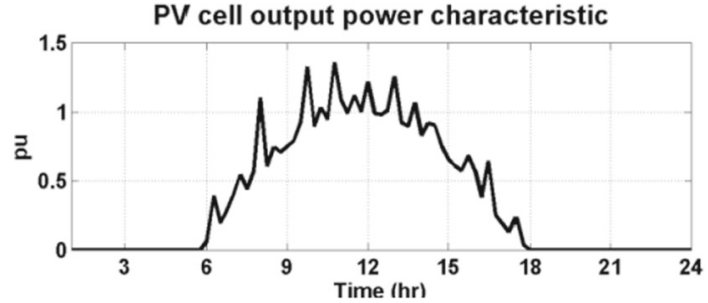

Fig. 6 The considered PV output power over a $24 \mathrm{~h}$ period

\section{Step 3: Voltage Unbalance Reduction by Active Power Curtailment}

The third step of the proposed control method is curtailing the output active power of the rooftop PVs, if the previous two steps were not sucessful in minimizing the non-standard voltage rise and voltage unbalance along the feeder. For this, the output active power of the PVs, dicatated by the maximum power point tracking (MPPT) algorithm $\left(P_{\mathrm{MPPT}}\right)$ will be delibertaley reduced at a specific bus to minimize voltage unbalance in the feeder. To do this, the active power output of the PV inverter is forced to be equal to the desired value of $P_{\mathrm{PV}, \text { ref }}$ calculated from [10]

$P_{\mathrm{PV}, \text { ref }}=P_{\mathrm{MPPT}}-n\left(V_{\mathrm{PCC}, \text { ref }}-V_{\mathrm{PCC}}\right)$

where $n>0$ is the curtailment coefficient that needs to be defined to minimize the difference between the magnitudes of all phase volatges. Note that this step runs with a time delay of $\Delta T_{2}$ (in few minutes range) where $\Delta T_{2}<\Delta T_{1}$.

In summary, the master controller of the VRT requires voltage rms values along the feeder in all three phases, which is acquired by the help of voltage sensors at the beginning and end of feeder and at each rooftop PV inverter, as shown in Fig. 2. However, the master controller does not need the information about the active/reactive power output of each rooftop PV system. The real-time active/reactive power output of a PV inverter is used locally in the controller of that PV only. Thus, the considered VRT is a decentralized control scheme.

\section{Monte Carlo-based Stochastic Analysis}

The developed stochastic framework consists of two steps for defining the uncertainties of load and PV. To model the uncertainties of the residential loads, the method presented in [20] is utilized which models each electric appliance in every house. It is considering different criteria such as the normal distribution of the power consumption of each appliance, random turning on/off time of each appliance, the presence of people in the house throughout the $24 \mathrm{~h}$ period, the ambient temperature on the operation time of 

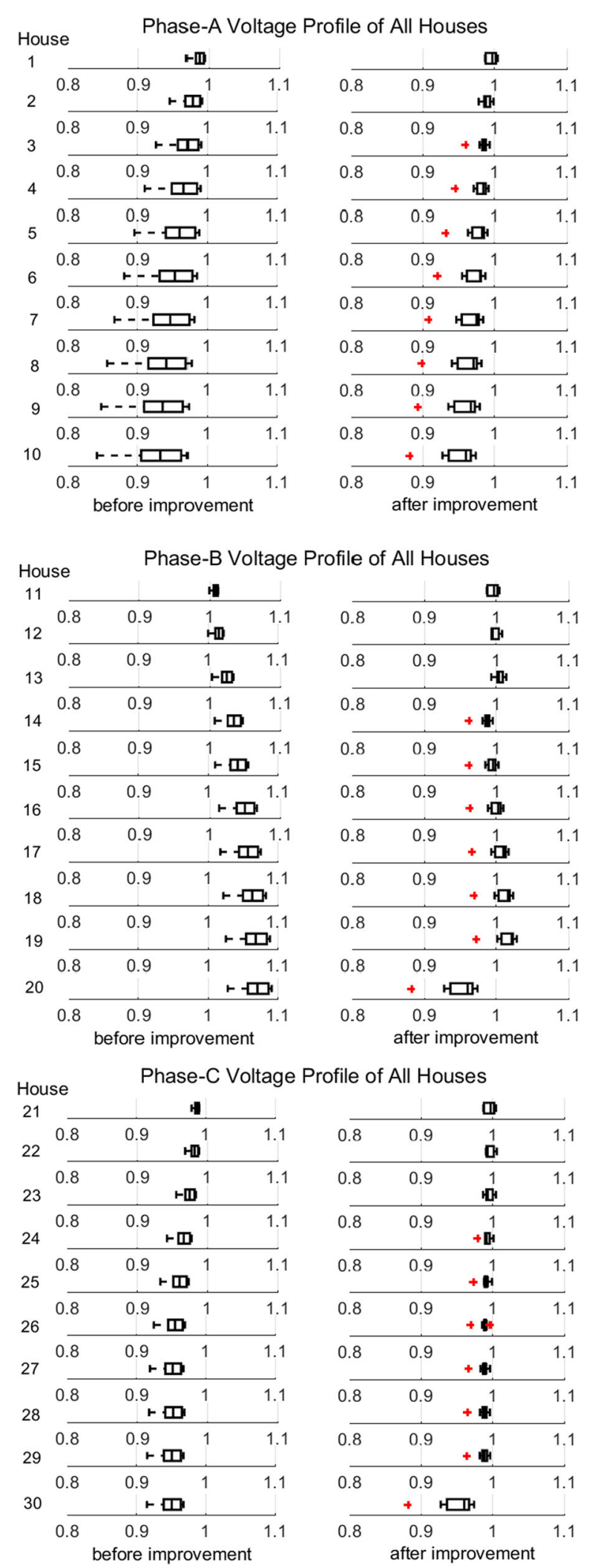

Fig. 7 Statistical data of phase voltages of all houses connected to phase-A, B and C before improvement (left column) and after applying the VRT (right column) assuming PV penetration level of $100 \%$
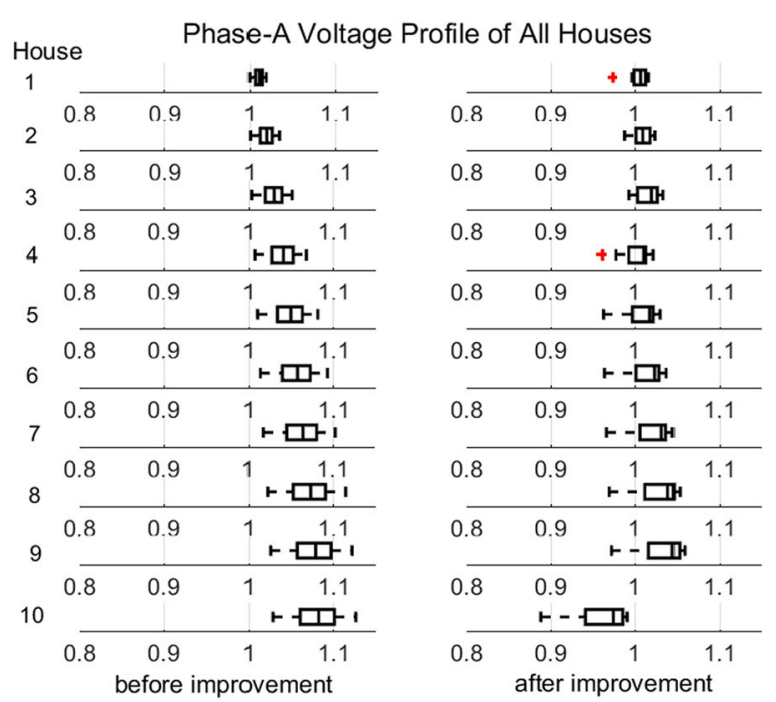

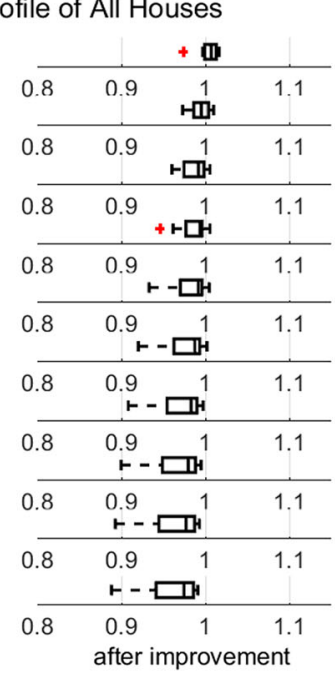

Phase-C Voltage Profile of All Houses

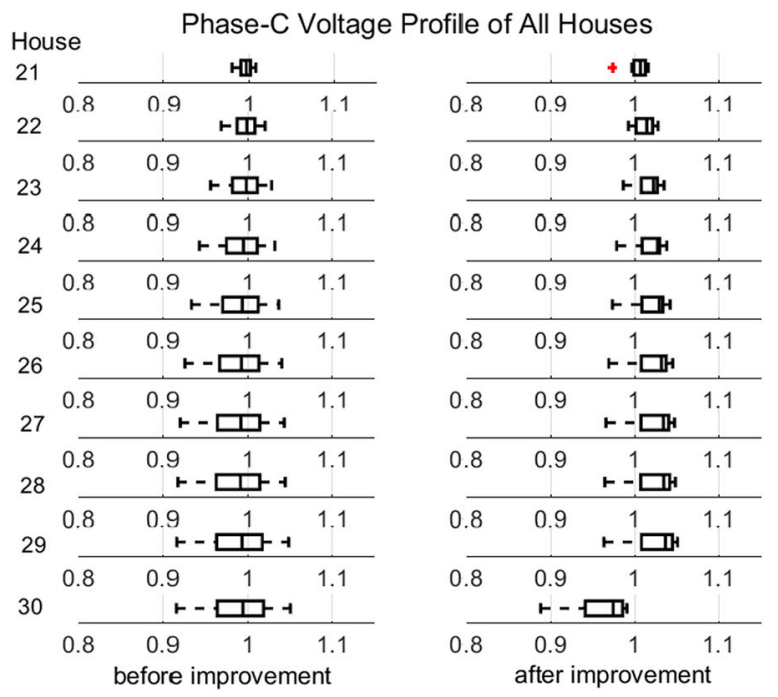

Fig. 8 Statistical data of phase voltages of all houses connected to phase-A, B and C before improvement (left column) and after applying the VRT (right column) assuming PV penetration level of $80 \%$ 

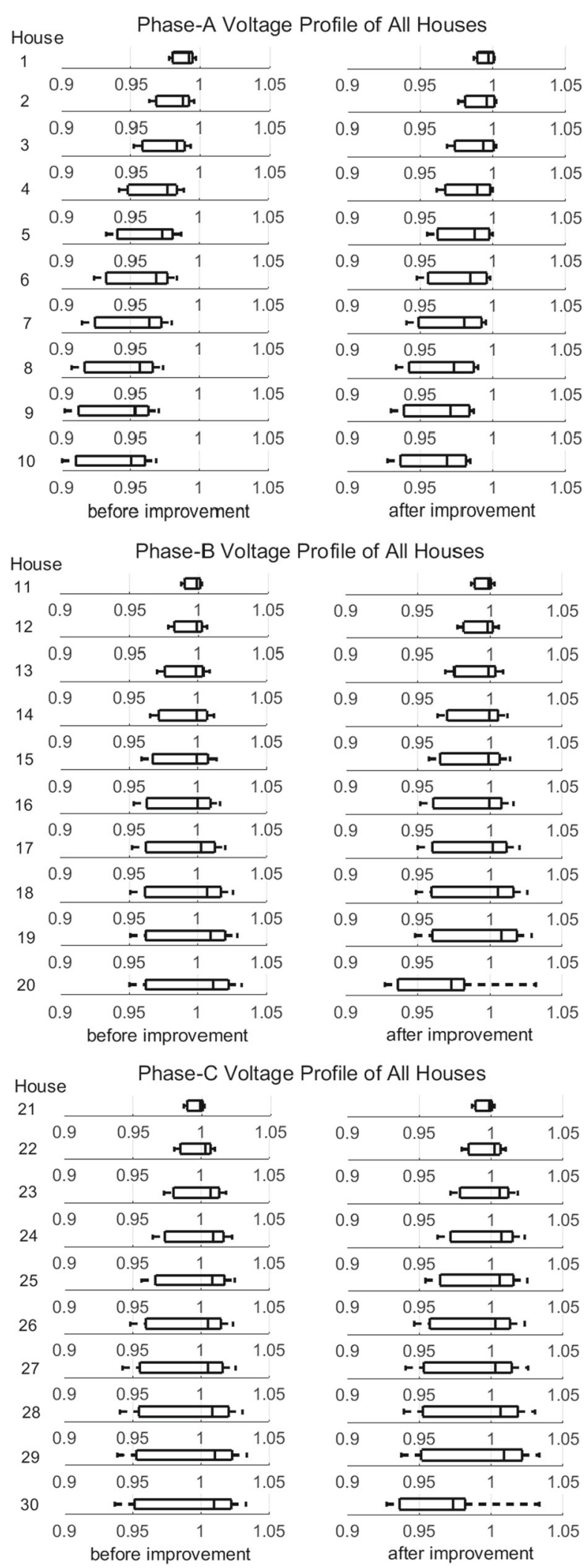

Fig. 9 Statistical data of phase voltages of all houses connected to phase-A, B and C before improvement (left column) and after applying the VRT (right column) assuming PV penetration level of 50\% the air conditioners, water-heaters, etc. Thereby, the summation of all electrical appliances in a house determines the total demand of that house over a $24 \mathrm{~h}$ period. The uncertainties of PV are modelled considering different criteria including the nominal power generation capacity of the PV cells, the nominal capacities of the PV inverter, location of the PVs in each phase of the feeder and the time of the day. Fig. 4 illustrates the Monte Carlo-based flowchart, used in this research. The Monte Carlo analysis is deemed to be converged once an acceptable convergence in the average and standard deviation is achieved in the total voltage unbalance factor $(T U V F)$ and maximum of voltage unbalance factor $\left(V U F_{\max }\right)$ of the feeder, that are defined respectively as

$$
\begin{aligned}
\text { TVUF } & =\sqrt{\sum_{i=1}^{N} V U F_{i}^{2}} / N \\
V U F_{\max } & =\max \left(V U F_{i}\right) \quad \forall i=1, \ldots, N
\end{aligned}
$$

where the voltage unbalance factor $(V U F)$ at bus- $i$ of a threephase four-wire system is calculated from [18]

$V U F_{i}=\sqrt{V_{-}^{2}+V_{0}^{2}} / \sqrt{V_{+}^{2}}$

and $V_{+}, V_{-}$and $V_{0}$ are respectively the positive, negative and zero sequence components of voltage at each bus, calculated from phase voltage measurements as [21]

$$
\begin{aligned}
& V_{+}=\left(V_{\mathrm{A}}+a V_{\mathrm{B}}+a^{2} V_{\mathrm{C}}\right) / 3 \\
& V_{-}=\left(V_{\mathrm{A}}+a^{2} V_{\mathrm{B}}+a V_{\mathrm{C}}\right) / 3 \\
& V_{0}=\left(V_{\mathrm{A}}+V_{\mathrm{B}}+V_{\mathrm{C}}\right) / 3
\end{aligned}
$$

and $a=1 \angle 120^{\circ}$. It is to be noted that to prevent immature convergence of the Monte Carlo analysis, a minimum of 1000 iterations are also imposed to the Monte Carlo analysis.

\section{Performance Evaluation}

To evaluate the performance of the discussed VRT under load and PV uncertainties, the network of Fig. 1 is considered as the test case. Let us assume that a $150 \mathrm{kVA}, 11 \mathrm{kV} / 415 \mathrm{~V}$ transformer supplies 30 houses, distributed equally among the phases.

The residential load profiles used in this analysis are calculated from the residential load modelling presented in [20]. As an example, the load profile of all houses are demonstrated in time-domain in Fig. 5a while probability density function (PDF) of those houses, over a $24 \mathrm{~h}$ period, are shown in box plot formats (i.e. statistical view) in Fig. 5b. Figure 5c illustrates the PDF histograms of those houses. It is to be noted that in the rest of this paper, only box plots are used to illustrate the data distribution. 
Fig. 10 Statistical data of phase voltages of all houses connected to phase-A, B and C before improvement (left column) and after applying the VRT (right column) assuming PV penetration level of $20 \%$
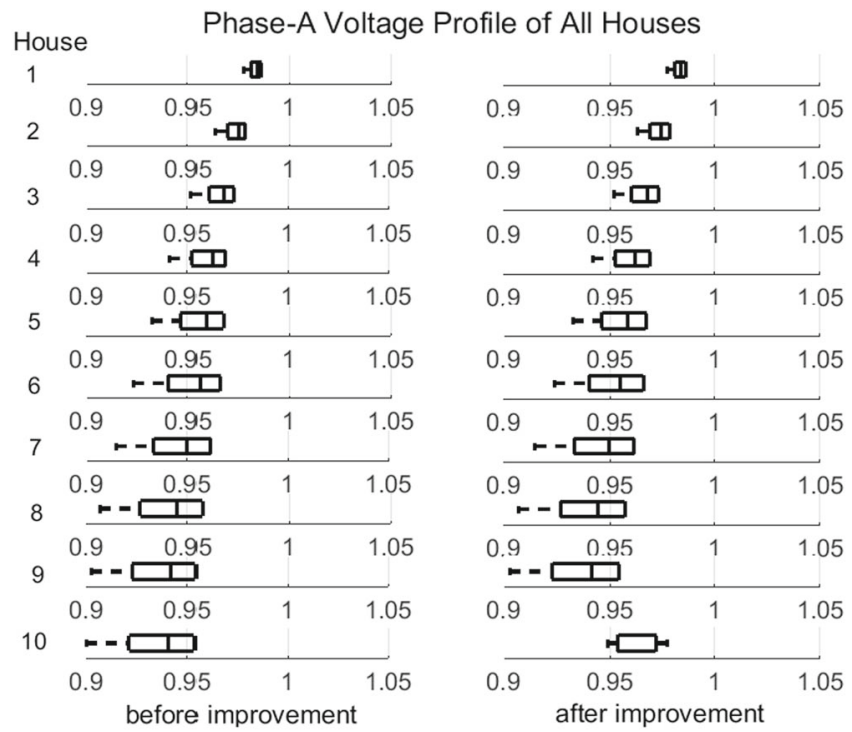

Phase-B Voltage Profile of All Houses
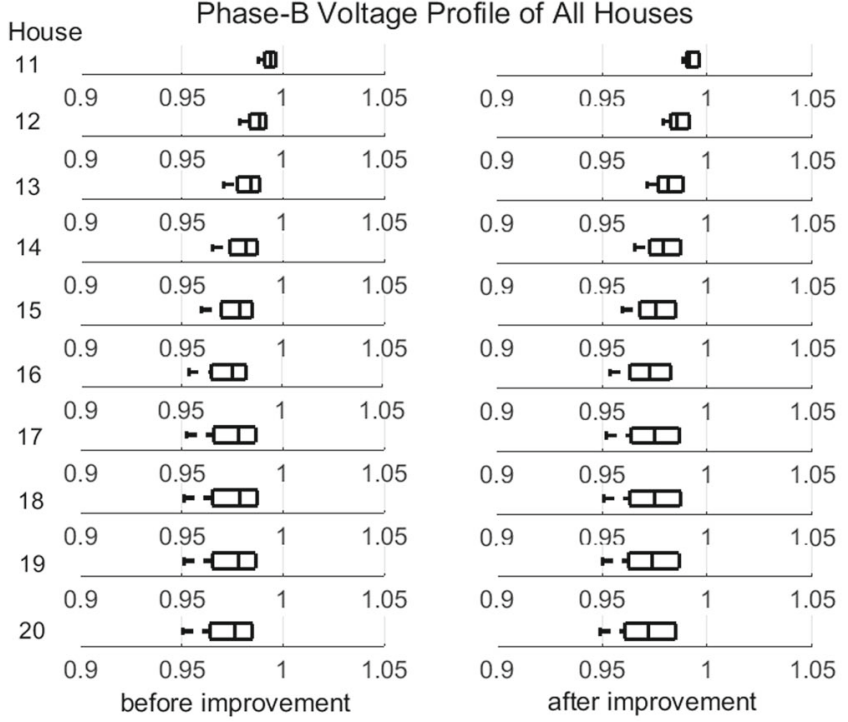

Phase-C Voltage Profile of All Houses

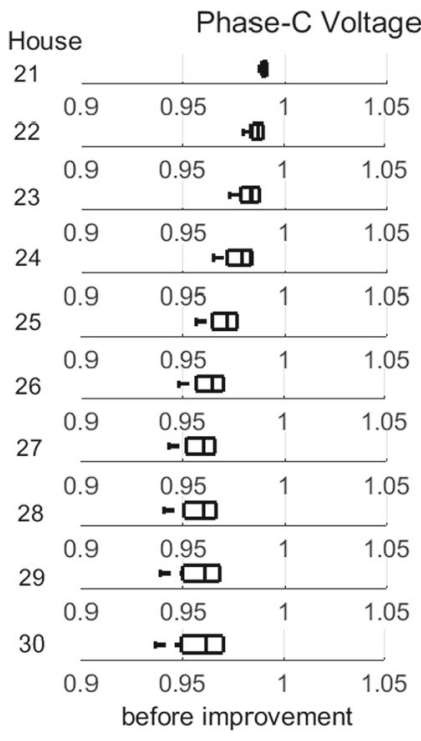


Fig. 11 Statistical comparison of $V U F_{\max }$ and $T V U F$ before and after applying the VRT for different PV penetration levels: $100 \%$ (first row), $80 \%$ (second row) $50 \%$ (third row) and $20 \%$ (fourth row)
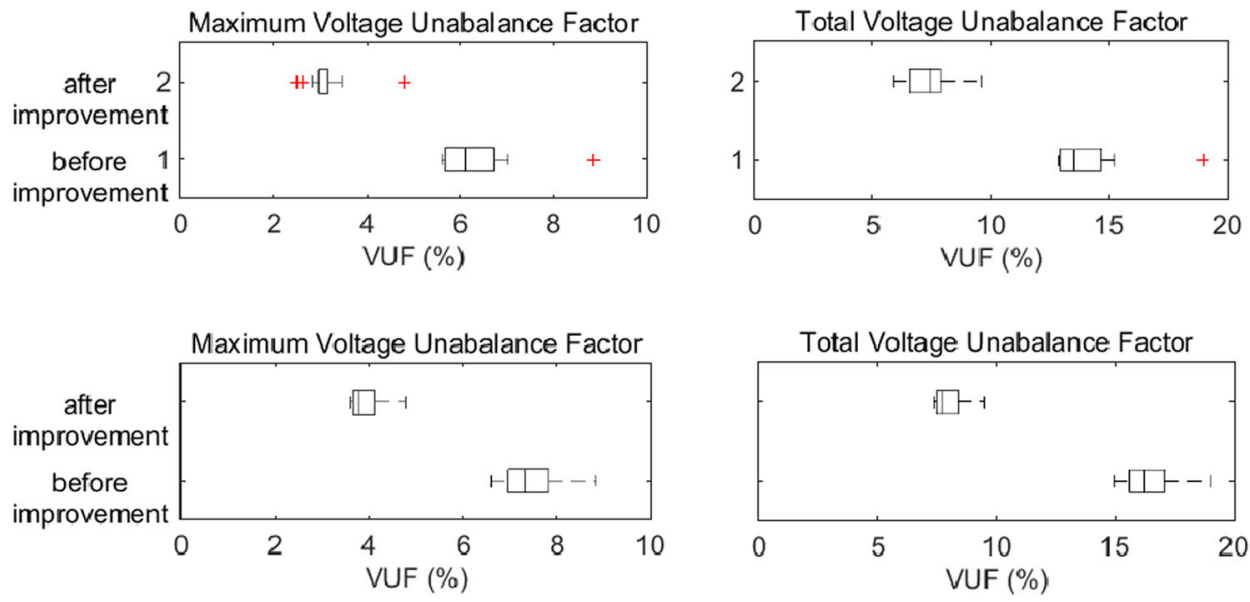

Total Voltage Unabalance Factor
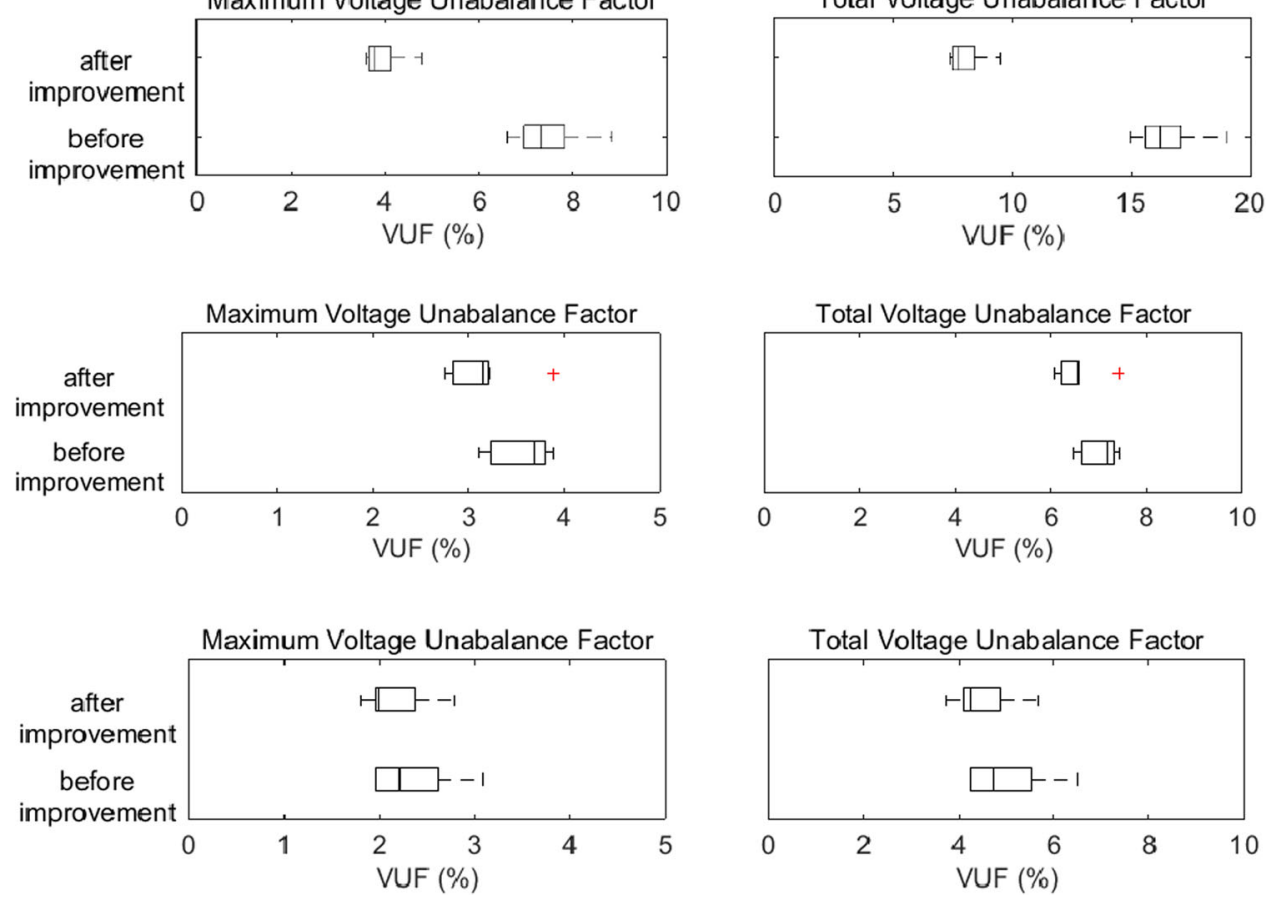

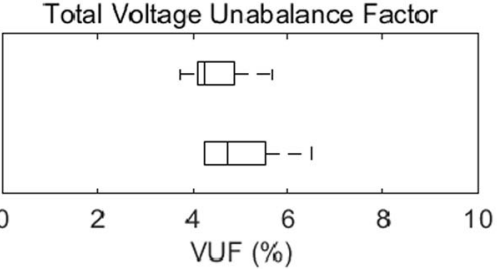

The PV cells are assumed to have an equivalent distribution of 1 to $5 \mathrm{~kW}$ while the PV inverters are assumed to have a capacity of $140 \%$ of the PV cells. In this study, the sunlight availability is assumed between 6 am and $6 \mathrm{pm}$ while the PVs generate their maximum output at $12 \mathrm{pm}$. To consider the clouds effect on the PV output power generation, a white noise signal is added to the output power of the PVs. Figiure 6 illustrates the considered PV output power for the duration of this study. Since the PVs are located in a close geographic area $(400 \mathrm{~m})$ the same PV output power characteristic is used for all considered PVs in the network.

First, let us consider a network with $100 \%$ PV penetration level (i.e. 1-5 kW PVs are allocated along the feeder). Figiure 7 illustrates the Monte Carlo-based statistical results for phase A, B and C voltages of each house separately in the original condition (i.e. before applying the VRT, at the left column) and after applying the improvement method (at the right column). It is to be noted that the phase voltages for each bus are illustrated in boxplot diagrams instead of the probability density functions. It is noteworthy that each boxplot shows the median of the data (i.e. the line within the box), the minimum and maximum of the observed voltages (i.e. the two end lines) and the box limits shows the interquartile range were below 1 per-unit $(\mathrm{pu})$ in the original condition and have improved to 1 pu after applying the VRT [22]. In addition, the minimum phase voltage observed for each house is also improved. A similar result is also observed for the buses of the houses connected to phase-C. This figure also shows that for the buses of houses connected to phase- $\mathrm{B}$, a high voltage rise was observed in the original case, but is reduced effectively after applying the VRT. Figures 8, 9 and 10 illustrate similar results when PV penetration levels of 80,50 and $20 \%$ are respectively considered.

Figure 11 illustrates the maximum of VUF and the total of VUF before and after applying the improvement method for each of the previous cases. These results illustrate the effective performance of the VRT even in the presence of the load and PV uncertainties.

Table 1 represents the median of $V U F_{\max }$ and $T V U F$ for each of these cases. This table illustrates that the discussed VRT can successfully reduce the expected maximum and total of VUF in the LV feeder under load and PV uncertainties 
Table 1 Expected mean of $V U F_{\max }$ and TVUF [\%] at different PV penetration level

\begin{tabular}{lllll}
\hline PV penetration & \multicolumn{2}{c}{ Before improvement } & \multicolumn{2}{c}{ After improvement } \\
\cline { 2 - 5 } level $(\%)$ & $V U F_{\max }$ & $T V U F$ & $V U F_{\max }$ & $T V U F$ \\
\hline 100 & 6.1 & 13.5 & 3 & 7.5 \\
80 & 7.4 & 16.1 & 3.7 & 7.9 \\
50 & 3.7 & 7.2 & 3.2 & 6.5 \\
20 & 2.2 & 4.6 & 2 & 4.4 \\
\hline
\end{tabular}

\section{Conclusion}

This paper has evaluated the performance of an intelligent and communication-based voltage regulation technique under a Monte Carlo-based stochastic framework to consider the effects of the load and PV uncertainties on the performance of the method. The considered VRT first tries to lower the tap position of the OLTC distribution transformer if nonstandard voltage rises is detected at the end of the feeder. It also defines proper reference voltages for the three phases of the network at each bus which will be utilized by the PV inverters and uses reactive power support and active power curtailment to regulate the PCC voltage of each PV inverter to the desired reference value. The Monte-carlo based stochastic results demonstrate that the proposed VRT in [10] is sucessful in minimizing the VUF in the LV feeder even considering the different load and PV generation uncertainaties. The results illustrate that the level of reduction in the maximum VUF and total VUF is higher as the PV penetration level is high but reduces as the PV penetration level in the network is reduced. Thus, it can be concluded that, by applying the proposed VRT, the penetration level of PVs can be allowed to increase while maintaining the voltage unabalance and voltage rise along the feeder within acceptable limits.

As a future research topic, the integeration of energy storage systems with rooftop PVs can be conisderted as an alternative for reducing the active power curtailement [23]. Thus, the VRT can be further modified to accommodate the presence and status of the energy storage systems in the LV feeders. Furthermore, a sequential Monte Carlo technique such as practical filtering can be used instead of Monte Carlo method, especailly when modelling unknown distributions, as they will avoid the impoverishment and convergence problems of the analysis [24]. Additionally, development of a control scheme for the rooftop PV inverters to facilitate the reactive power exchange and active power curtailment using estimation schemes, based on disturbance observers [25], can be suggested as a future research topic.

\section{Appendix 1}

The parameters of the simulated test network in Fig. 1 are provided in Table 2.

Table 2 Technical parameters of the simulated test network of Fig. 1

\begin{tabular}{lc}
\hline Transformer & $11 / 0.415 \mathrm{kV}, 50 \mathrm{~Hz}, 150 \mathrm{kVA}, 50 \mathrm{~Hz}, \mathrm{Dyn}$, \\
& $z=0.05 \mathrm{pu}$ \\
MV feeder & $11 \mathrm{kV} \mathrm{L}-\mathrm{Lrms}, 3$-phase 3-wire, $5 \mathrm{~km}, 1.08+$ \\
& $j 0.0302 \Omega / \mathrm{km}$ \\
LV feeder & $415 \mathrm{~V} \mathrm{~L}-\mathrm{Lrms}, 3$-phase 4-wire, $400 \mathrm{~m}, 0.452$ \\
& $+j 0.270 \Omega / \mathrm{km}$ \\
\hline
\end{tabular}

\section{Appendix 2}

An unbalanced sweep forward-backward load flow method [19] is developed in MATLAB and uses for the analysis of the three-phase four-wire radial LV network under consideration. The load flow calculates the bus voltages along the feeder.

First, modified Carson's equations [26] are utilized for calculation of self and mutual impedance of the conductors in $50 \mathrm{~Hz}$ system as

$$
Z_{i i}=r_{i}+0.04934+j 0.062832\left[7.10988-\operatorname{Ln}\left(G M R_{i}\right)\right]
$$

$Z_{i j} t=0.04934+j 0.062832\left[7.10988-\operatorname{Ln}\left(D_{i j}\right)\right]$

where $i$ and $j$ are the phase conductor (i.e., A, B, C or Neutral), $Z_{i i}$ is the self-impedance of conductor $i$ (in $\Omega / \mathrm{km}$ ), $Z_{i j}$ is the mutual impedance between two conductors $i$ and $j$ (in $\Omega / \mathrm{km}$ ), $r_{i}$ is the ac resistance of conductor $i$ (in $\Omega / \mathrm{km}$ ), $\mathrm{GMR}_{i}$ is the geometric mean radius of conductor $i$ (in $\mathrm{cm}$ ) and $D_{i j}$ is the distance between conductors $i$ and $j$ (in $\mathrm{cm}$ ). Hence, the non-transposed characteristics of the conductors, image conductors below ground and network configuration are considered in the studies. Fig. 12a shows the considered line configuration in this study [26].

The three-phase four-wire line segment between two adjacent buses of $k-1$ and $k$ is also shown in Fig. 12b. From (10) and (11), the equivalent impedance for the line section shown in Fig. 12b is expressed as:

$\left[\mathbf{Z}_{a b c n}\right]=\left[\begin{array}{cccc}Z_{a a} & Z_{a b} & Z_{a c} & Z_{a n} \\ Z_{b a} & Z_{b b} & Z_{b c} & Z_{b n} \\ Z_{c a} & Z_{c b} & Z_{c c} & Z_{c n} \\ Z_{n a} & Z_{n b} & Z_{n c} & Z_{n n}\end{array}\right]$

Assuming the transformer has delta/wye-grounded configuration and using Kron reduction, (12) can be rewritten as 
(a)

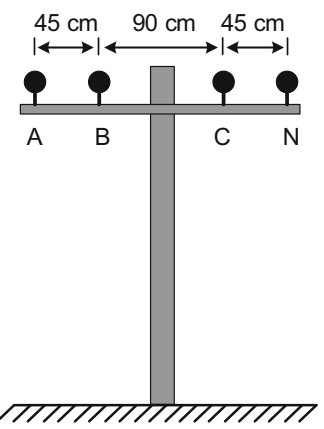

(b)

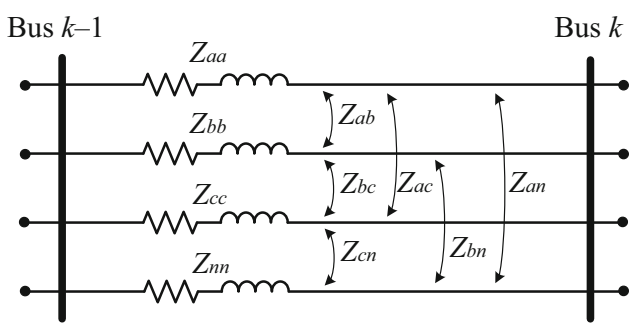

(c)

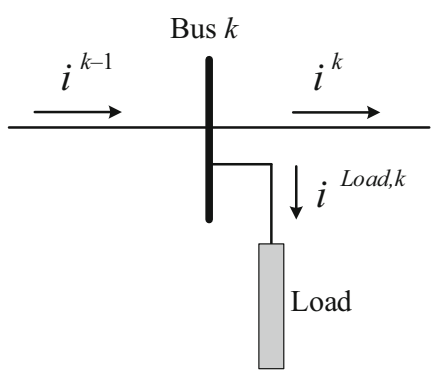

Fig. 12 a LV feeder configuration. b Impedance equivalent of a line segment between two buses. $\mathbf{c}$ PQ bus model

$\left[\mathbf{Z}_{a b c}\right]=\left[\begin{array}{lll}Z_{a a-n} & Z_{a b-n} & Z_{a c-n} \\ Z_{b a-n} & Z_{b b-n} & Z_{b c-n} \\ Z_{c a-n} & Z_{c b-n} & Z_{c c-n}\end{array}\right]$

All calculations are carried out in pu. Starting with a set of initial values (e.g. a flat voltage set), the load currents are calculated as

$\left[\mathbf{I}_{a b c}^{L o a d, k}\right]=\left(\left[\mathbf{P}_{a b c}^{L o a d, k}\right]-j\left[\mathbf{Q}_{a b c}^{L o a d, k}\right]\right) / \operatorname{conj}\left(\left[\mathbf{V}_{a b c}^{k}\right]\right)$

currents connected to bus $k,\left[\mathbf{V}_{a b c}^{k}\right]$ is a vector of three-phase voltages of bus $k,\left[\mathbf{P}_{a b c}^{L o a d, k}\right]$ and $\left[\mathbf{Q}_{a b c}^{L o a d, k}\right]$ are respectively the vectors of three-phase active and reactive power consumption of residential load connected to bus $k$ and $\operatorname{conj}()$ represents the conjugate operator.

The sum of the all load currents will flow from the first bus (i.e. transformer secondary side) to the second bus. Therefore, as shown in Fig. 12c, the current between two adjacent buses is

$\left[\mathbf{I}_{a b c}^{k}\right]=\left[\mathbf{I}_{a b c}^{k-1}\right]-\left[\mathbf{I}_{a b c}^{L o a d, k}\right]$

Hence, the voltage of bus $k$ can be calculated based on the voltage of bus $k-1$ in its upstream and the current passing between two buses as

$\left[\mathbf{V}_{a b c}^{k}\right]=\left[\mathbf{V}_{a b c}^{k-1}\right]-\left[\mathbf{Z}_{a b c}\right]\left[\mathbf{I}_{a b c}^{k}\right]$

Once the voltage at bus $k$ is calculated, the load current in that bus will be updated from (14) and then using (15) the current flowing from bus $k$ to $k+1$ in its downstream are updated.

Similar to the line segment, the equivalent impedance of the delta/wye-grounded distribution transformer between its primary and secondary buses is expressed as

$\left[\mathbf{Z}_{a b c}^{k}\right]=z_{t} \times \mathbf{I}_{3}$

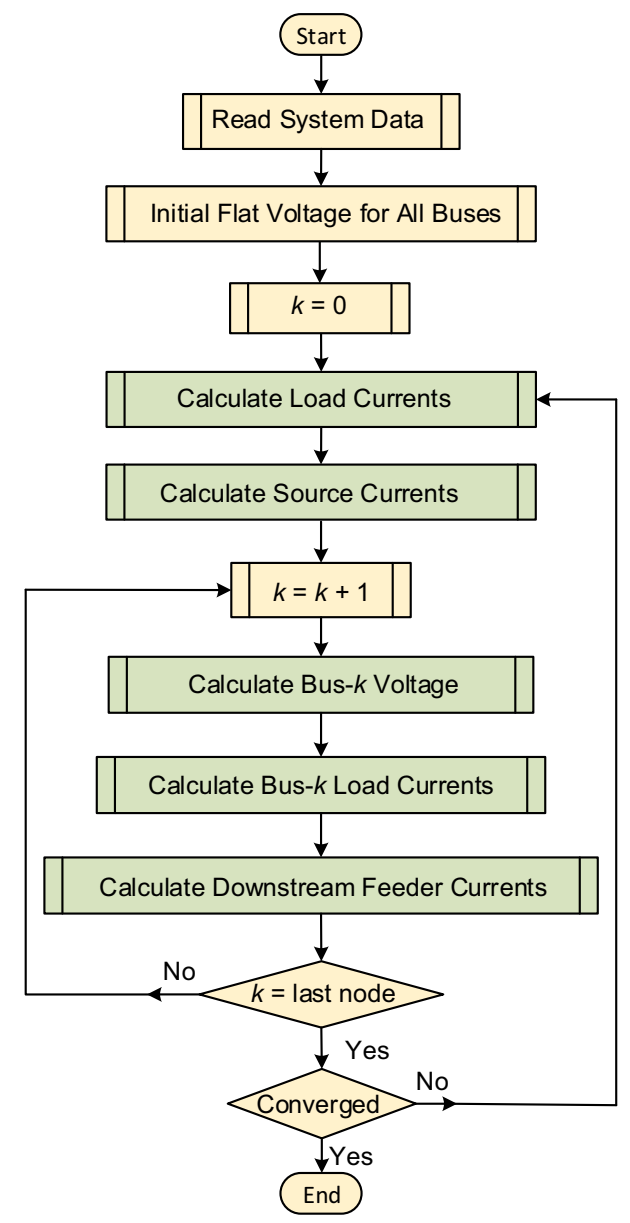

Fig. 13 Flowchart of developed unbalanced load flow analysis

where $z_{t}$ is the phase impedance of the transformer and $\mathbf{I}_{3}$ is the identity matrix of $3 \times 3$. Now, th secondary-side voltage of the transformer are calculated from its primary-side voltage as [26]

$\left[\mathbf{V} t_{a b c}^{S}\right]=[\mathbf{A}]\left[\mathbf{V} t_{a b c}^{P}\right]-\left[\mathbf{Z} t_{a b c}\right]\left[\mathbf{I}_{a b c}\right]$

where $\left[\mathbf{V} t_{a b c}^{P}\right]$ and $\left[\mathbf{V} t_{a b c}^{S}\right]$ are respectively the primary and secondary-side phase voltages of the transformer and $\left[\mathbf{I}_{a b c}\right]$ 
is a vector of three-phase current passing through the transformer and

$[\mathbf{A}]=\frac{1}{\sqrt{3}}\left[\begin{array}{ccc}1 & 0 & -1 \\ -1 & 1 & 0 \\ 0 & -1 & 1\end{array}\right]$

The flowchart of the load flow method is shown in Fig. 13.

\section{References}

1. Shahnia, F., Ghosh, A., Ledwich, G., Zare, F.: Voltage unbalance reduction in low voltage distribution networks with rooftop PVs. 20th Australasian Universities Power Engineering Conference (AUPEC), pp. 1-5. (2010)

2. Trichakis, P., Taylor, P.C., Lyons, P.F., Hair, R.: Predicting the technical impacts of high levels of small-scale embedded generators on low-voltage networks. IET Renew. Power Generat. 2, 249-262 (2008)

3. Shahnia, F., Majumder, R., Ghosh, A., et al.: Voltage imbalance analysis in residential low voltage distribution networks with rooftop PVs. Electr. Power Syst. Res. 81(9), 1805-1814 (2011)

4. Chidurala, A., Saha, T., Mithulananthan, N.: Harmonic characterization of grid connected PV systems and validation with field measurements. IEEE Power and Energy Society General Meeting, pp. 1-5. (2015)

5. Zhong, Q.C., Weiss, G.: Synchronverters: inverters that mimic synchronous generators. IEEE Trans. Ind. Electr. 58(4), 1259-1267 (2011)

6. Xiangjing, S., Masoum, M.A.S., Wolfs, P.J.: Optimal PV inverter reactive power control and real power curtailment to improve performance of unbalanced four-wire lv distribution networks. IEEE Trans. Sustain. Energy 5(3), 967-977 (2014)

7. Tonkoski, R., Lopes, L.A.C., El-Fouly, T.H.M.: Droop-based active power curtailment for overvoltage prevention in grid connected PV inverters. IEEE International Symposium on Industrial Electronics (ISIE), pp. 2388-2393. (2010)

8. Shahnia, F., Ghosh, A.: Decentralized voltage support in a low voltage feeder by droop based voltage controlled PVs. IEEE 23rd Australasian Universities Power Engineering Conference (AUPEC), pp. 1-6. (2013)

9. Kabiri, R., Holmes, D.G., McGrath, B.P.: Voltage regulation of LV feeders with high penetration of PV distributed generation using electronic tap changing transformers. IEEE 24thAustralasian Universities Power Engineering Conference (AUPEC), pp. 1-6. (2014)

10. Safitri, N., Shahnia, F., Masoum, M.A.S.: Coordination of singlephase rooftop PVs in unbalanced three-phase residential feeders for voltage profiles improvement. Accepted and to be Published in Australian Journal of Electrical and Electronics Engineering (2015)

11. Vallée, F., Klonari, V., Lisiecki, T., et al.: Development of a probabilistic tool using Monte Carlo simulation smart meters measurements for the long term analysis of low voltage distribution grids with photovoltaic generation. Electr. Power Energy Syst. 53, 468-477 (2013)
12. $\mathrm{Du}, \mathrm{W} .:$ Model validation by statistical methods on a Monte Carlo simulation of residential low voltage grid. Future Communication, Computing, Control and Management, LNEE 142, pp. 93-98. Springer, Heidelberg (2012)

13. Du, W.: Probabilistic analysis for capacity planning in smart grid at residential low voltage level by Monte Carlo method. Electr. Power Energy Syst. 23, 804-812 (2011)

14. Widen, J., Wackelgard, E., Paatero, J., Lund, P.: Impacts of distributed photovoltaics on network voltages: stochastic simulations of three Swedish low-voltage distribution grids. Electr. Power Syst. Res. 80, 1562-1571 (2010)

15. Navarro, A., Ochoa, L.F., Randles, D.: Monte Carlo-based assessment of PV impacts on real UK low voltage networks. IEEE Power and Energy Society General Meeting, pp. 1-7. (2013)

16. Torquato, R., Shi, Q., Xu, W., Freitas, W.: A Monte Carlo simulation platform for studying low voltage residential networks. IEEE Trans. Smart Grid 5(6), 2766-2776 (2014)

17. Earthling of the distribution network, Technical Standard, SA Power Networks. http://www.sapowernetworks.com.au/public/ download.jsp?id=30570\&page=/centric/industry/contractors_and_ designers/technical_standards.jsp (2014)

18. Low Voltage Overhead Distribution Construction Standards Handbook, Western Power. http://www.westernpower.com.au/docu ments/low-voltage-overhead-distribution-construction-standardshan.pdf (2007)

19. Safitri, N., Shahnia, F., Masoum, M.A.S.: Different techniques for simultaneously increasing the penetration level of rooftop PVs in residential LV networks and improving voltage profile. 6th IEEE PES Asia-Pacific Power and Energy Engineering Conference (APPEEC), pp. 1-5. Hong Kong, (2014)

20. Shahnia, F., Wishart, M.T., Ghosh, A., Ledwich, G.: Smart distributed demand side management of low voltage distribution networks using multi-objective decision making. IET Generat. Trans. Distrib. 6(10), 968-1000 (2012)

21. Shahnia, F., Wolfs, P.J., Ghosh, A.: Voltage unbalance reduction in low voltage feeders by dynamic switching of residential customers among three phases. IEEE Trans. Smart Grid 5(3), 1318-1327 (2014)

22. Upton, G., Cook, I.: Understanding Statistics. Oxford University Press, Oxford (1996)

23. Telaretti, E., Sanseverino, E.R., Ippolito, M., et al.: A novel operating strategy for customer-side energy storages in presence of dynamic electricity prices. Intell. Ind. Syst. 1(3), 233-244 (2015)

24. Doucet, A., de Freitas, N., Gordon, N.: Sequential Monte Carlo Methods in Practice. Springer, Weinan (2001)

25. Rigatos, G., Siano, P., Zervos, N., Cecati, C.: Decentralized control of parallel inverters connected to microgrid using the Derivativefree nonlinear Kalman Filter. IET Power Electr. 8(7), 1164-1180 (2015)

26. Kersting, W.H.: Distribution System Modeling and Analysis. CRC Press, Boca Raton (2012) 